\title{
Polymerase Chain Reaction (PCR)-Based Sex Determination Using Unembalmed Human Cadaveric Skeletal Fragments From Sokoto, Northwestern Nigeria.
}

\author{
*Zagga Ad, ${ }^{\mathrm{A}}$ Tadros Aa, ${ }^{\mathrm{A}}$ Ismail Sm, ${ }^{\mathrm{B}}$ And Ahmed H, Oon. ${ }^{\mathrm{C}}$ \\ ${ }^{A}$ Department of Anatomy, College of Health Sciences, Usmanu Danfodiyo University, Sokoto, Sokoto State, \\ Nigeria. \\ ${ }^{B}$ Department of Medical Molecular Genetics, Division of Human Genetics and Genome Research, National \\ Research Centre, Cairo, Egypt. \\ ${ }^{C}$ Department of Paediatrics, College of Health Sciences, Usmanu Danfodiyo University, Sokoto, Sokoto State, \\ Nigeria.
}

\begin{abstract}
The strategy developed for sex determination in skeletal remains is to amplify the highly degraded $D N A$, by use of primers that span short DNA fragments. To determine sex of unembalmed human cadaveric skeletal fragments from Sokoto, North-western Nigeria, using Polymerase Chain Reaction (PCR). A single blind study of Polymerase Chain Reaction (PCR)-based sex determination using amelogenin gene and alphoid repeats primers on unembalmed human cadaveric skeletal fragments from Sokoto, North-western Nigeria, was undertaken. With amelogenin gene, genetic sex identification was achieved in four samples only. PCR Sensitivity $=40 \%$, Specificity $=100 \%$, Predictive value of positive test $=100 \%$, Predictive value of negative test $=25 \%$, False positive rate $=0 \%$, False negative rate $=150 \%$, Efficiency of test $=50 \%$. Fisher's exact probability test $\boldsymbol{P}=1$. Z-test: $z$-value $=-1.0955, \boldsymbol{p}>0.05$; not statistically significant. With alphoid repeats primers, correct genetic sex identification was achieved in all the samples. PCR Sensitivity $=100 \%$, Specificity $=0 \%$, Predictive value of positive test $=100 \%$, Predictive value of negative test $=0 \%$, False positive rate $=$ $0 \%$, False negative rate $=0 \%$, Efficiency of test $=100 \%$. Fisher's exact probability test $\boldsymbol{P}=1$. Z-test: $z$ - and $\boldsymbol{p}$ values were invalid. The study, has demonstrated the applicability of PCR method of sex determination in unembalmed human skeletal fragments from Sokoto, Northwestern Nigeria. With amelogenin gene primers, correct genetic sex identification was achieved in four samples only. With alphoid repeats primers, correct genetic sex identification was achieved in all the samples. Therefore, alphoid repeats is more efficient and more reliable than amelogenin gene, in sex determination from unembalmed human skeletal fragments. This is the first known study determining the sex of unembalmed human skeletal fragments by means of PCR in Nigeria. There is need for further studies in Nigeria to complement the findings of this study.
\end{abstract}

Key words: PCR, sexing, bones, Sokoto, Nigeria.

\section{Introduction}

Bones are an important source to obtain genetic material since they are inner the body and because their mineral condition, which cortical protects the medullar part from external factors and micro organisms that may degrade the DNA [1]. In mass disaster situations, Andelinovic et al (2005) [2], presented that DNA analysis from bone and tooth material allowed identify 109 victims of 12 year war in the former Yugoslavia. Traditional identification methods would not give such good results [3]. DNA analysis from bones and teeth would also guide anthropologic studies to identify population migration origin in ancient times [4,5]. Even though sample integrity is a fundamental factor in DNA extraction, studies with degraded biological material showed to be possible to analyze genetic material when it is fragmented (200 to 1200 pair bases) [6-8].

PCR is an in vitro method for the enzymatic amplification of specific DNA sequences, using two oligonucleotide primers that hybridize two opposite strands of the DNA, and flank the region of interest in the target DNA. A repetitive series of cycles involving template denaturation, primer annealing, and the extension of the annealed primers using DNA polymerase, results in the exponential accumulation of the specific fragment that is being sought. Assay time is reasonably short [9]. PCR analysis for forensic purposes has been applied to parentage testing, sex determination and species identification [10]. As DNA is often only present in forensic specimen in trace amounts, this method is of great value as it can theoretically be used to detect genetic material from as little as a single cell. ${ }^{(9)}$ Because of the margin of error in the known metrical and non-metrical methods, it is necessary to use more sensitive and accurate methods to identify sex from tissue [11].

The general objective of this study was therefore, to use PCR-based method to identify sex of unembalmed human cadaveric skeletal fragments, from Sokoto, Northwestern Nigeria. 


\section{Materials and Methods}

A total of twelve (12) unembalmed human (cadaveric) skeletal fragments from the carpus and phalanges of the hand and foot were used in this study. They comprised of: (1) Little finger (2) Capitate (3) Lunate (4) Hamate (5) Trapezium (6) Scaphoid (7) Middle finger (8) Small toe (9) Triquatrum (10) Pisiform (11) Trapezoid (12) Index finger.

This study was a single blind type. Information about the morphological sex of the samples was withheld from me by my supervisors and my colleagues. Samples were collected by my colleagues from preembalmed cadavers for dissection in the Department of Anatomy, College of Health Sciences, Usmanu Danfodiyo University, Sokoto, Nigeria, and handed over to me (the investigator).

The laboratory experiment was carried out at the Department of Medical Molecular Genetics, Division of Human Genetics and Genome Research, National Research Centre, Cairo, Egypt.

The protocol for precaution against contamination was based on the method employed by Cooper and Poinar, (2000), ${ }^{(12)}$ with minimal modification. While Cooper and Poinar, (2000) [12] used separate rooms for DNA extraction and PCR amplification, we used same room for these, but under two different hoods. Specific and stringent precautions were undertaken to handle specimen during DNA extraction and amplification. Specimen were handled (using disposable masks, gloves and laboratory coats) in an area where no other DNA studies were simultaneously carried out. The DNA extraction and the setting up of PCR reactions of DNA templates were carried out under two different hoods, daily irradiated with UV rays (254nm). Only disposable sterile tubes, filtered tips, sterile reagents and solutions, exclusively dedicated for DNA studies, were used. A set of pipettes, once used was not used again for DNA extraction, PCR amplification and analysis of the PCR products.

Samples of unembalmed cadaveric skeletal fragments were initially placed in a freezer (Elite. Air Multi=flow. Freezer and Refrigerator. No frost) at $-20^{\circ} \mathrm{C}$ (for minimum of 72 hours) to eliminate surface contamination from the depositional environment and post depositional handling. The equipment and surface of the hood were cleaned with distilled water, sterilised with 70\% ethanol (Art-Nr. K928.3 ROTH. Ethanol vergällt. $\geq 99.8 \%$, mit Ca. $1 \%$ MEK. Carl Roth $\mathrm{GmbH}+$ Co. KG. 2.5L. Schoemperslenstr. 3-5, 76185 Karlsruhe) and UV irradiated before and after grinding each sample. A sheet of aluminium foil (Helwan Aluminium Foil. 15M x 40CM. Made in Egypt) sterilized with 70\% ethanol (Art-Nr. K928.3 ROTH. Ethanol vergällt. $\geq 99.8 \%$, mit Ca. 1\% MEK. Carl Roth GmbH + Co. KG. 2.5L. Schoemperslenstr. 3-5, 76185 Karlsruhe) was placed on the surface of the hood.

About $0.5 \mathrm{~cm} \times 0.5 \mathrm{~cm}$ from each of the 12 bone samples was fragmented using sterile bone cutter and forceps (CE Stainless Pakistan). Samples were further sterilised with $70 \%$ ethanol and a sterile soft tissue was used to absorb excess ethanol from the sample (to dry the sample and minimize the PCR inhibitory effect of alcohol) before grinding. Each sample (one sample at a time) was then placed in a sterile mortar and pestle (MN $100 \mathrm{cl}$ ), for pulverization. Pulverization continued until the bone fragment turned into powder form. Aliquot of the ground bone powder was then transferred into $1.5 \mathrm{ml}$ microtubes $(1.5 \mathrm{ml}$ microcentrifuge tubes (Bio Basic Inc. (BBI). Cat. No. BT620NS - 100. Sterilized $1.5 \mathrm{ml}$ microcentrifuge certified RNase DNase and pyrogen free. Lot. No. 08112), already labelled (sample number, name of sample and date) on the flat white cap writing surfaces and on the sides with a permanent marker (STAEDTLER permanent Lumocolor Art. Nr. 313-3. EAN 4007817 308677), placed in a microtube rack (LP ITALIANA SPA - Milano/made in Italy) and stored in a refrigerator (Elite. Air Multi=flow. Freezer and Refrigerator. No frost) at $-80^{\circ} \mathrm{C}$, before DNA extraction.

The extraction of DNA from all the samples was done by standard phenol-chloroform method for bones, established by the Department of Medical Molecular Genetics, Division of Human Genetics and Genome Research, National Research Centre, Cairo, Egypt [13]. The samples consisted of about 0.3mg aliquot of the ground bone powder.

PCR amplification of the extracted DNA for sex determination from samples used previously prescribed amelogenin gene multiplex primers by Faerman et al., 1995 [14] and Matheson and Loy, 2001 [15] and alphoid repeats primers by Witt and Erickson, 1989 [16] and Murakami et al., 2000 [17].

A PCR master mix was prepared in a single $0.5 \mathrm{ml}$ PCR tube from: $2.5 \mu \mathbf{l}$ of 10x Buffer, $2.5 \mu \mathbf{l}$ of dNTPs, $2.5 \mu \mathrm{l}$ of $\mathrm{MgCl}_{2}, 4 \mu \mathrm{l}$ of forward primer M4, $2 \mu \mathrm{l}$ of $\mathrm{X}$ reverse primer M5 and $2 \mu \mathrm{l}$ of $\mathrm{Y}$ reverse primer M6, $1.25 \mu \mathrm{l}$ of Taq polymerase and $6.25 \mu \mathrm{l}$ of DEPC water. A total volume of $23 \mu \mathrm{l}$ from the master mix was transferred into $120.25 \mathrm{ml}$ microtubes. $1 \boldsymbol{\mu l}$ Paraffin oil was added to seal and avoid evaporation of the reaction mixture. $2 \mu$ l DNA (template) from the respective 12 samples was finally added to accomplish a reaction volume of $\mathbf{2 5} \boldsymbol{\mu l}$ for each tube.

Normal PCR was accomplished in a thermocycler (Minicycler ${ }^{\mathrm{TM}}$ MJ RESARCH), in a $\mathbf{2 5} \boldsymbol{\mu l}$ reaction volume, to amplify selected sequences of the amelogenin gene, as follows; Denaturation step: was at $94^{\circ} \mathrm{C}$ for 1 minute. Annealing step: was at $55^{\circ} \mathrm{C}$ for 2 minutes. Extension/elongation step: was at $72^{\circ} \mathrm{C}$ for 2 minutes. The above first three steps were repeated for 40 cycles. Final extension/elongation: was at $72^{\circ} \mathrm{C}$ for 15 minutes. Cooling of the reaction process: was at $4{ }^{\circ} \mathrm{C}$ for 48 hours. 
Amplification with alphoid repeats primers was prepared separately each for $\mathrm{X}$ (X1 and $\mathrm{X} 2$ ) primers, and Y (Y11 and Y22) primers, respectively, in separate $0.5 \mathrm{ml} \mathrm{PCR} \mathrm{tubes.} \mathrm{The} \mathrm{master} \mathrm{mix} \mathrm{for} \mathrm{each} \mathrm{of} \mathrm{X} \mathrm{and} \mathrm{Y}$ chromosomes was separately constituted from: $2.5 \mu \mathrm{l}$ of 10x buffer, $2.5 \mu \mathrm{l}$ of dNTPs, $2.5 \mu \mathrm{l}$ of forward primer for $\mathbf{X}=\mathrm{X} 1,2.5 \mu \mathrm{l}$ of reverse primer for $\mathrm{X}=\mathrm{X} 2,2.5 \mu \mathrm{l}$ of forward primer for $\mathrm{Y}=\mathrm{Y} 11,2.5 \mu \mathrm{l}$ of reverse primer for $\mathrm{Y}=\mathrm{Y} 22,0.5 \mu \mathrm{l}$ of Taq DNA polymerase and $17.5 \mu \mathrm{l}$ of DEPC water. A total volume of $\mathbf{3 3} \boldsymbol{\mu l}$ from the master mix was transferred into 12 tubes, for $\mathrm{X}$ and $\mathrm{Y}$, respectively and $\mathbf{1} \boldsymbol{\mu l}$ Paraffin oil added to seal and avoid evaporation of the reaction mixture. A volume of $\mathbf{2} \boldsymbol{\mu l}$ DNA from the respective 12 samples was finally added to the 12 tubes (containing PCR reagents for $\mathrm{X}$ and $\mathrm{Y}$ respectively), to accomplish a reaction volume of $\mathbf{3 5} \boldsymbol{\mu l}$ for each tube.

Normal PCR was accomplished in a thermocycler (Minicycler ${ }^{\mathrm{TM}} \mathrm{MJ}$ RESARCH in a $\mathbf{3 5} \boldsymbol{\mu l}$ reaction volume, to amplify selected sequences of the alphoid repeats, as follows; Initialization step at $95{ }^{\circ} \mathrm{C}$ for 5 minutes. Denaturation step at $94{ }^{\circ} \mathrm{C}$ for 40 seconds. Annealing step at $55{ }^{\circ} \mathrm{C}$ for 40 seconds. Extension/elongation step at $72^{\circ} \mathrm{C}$ for 40 seconds. Steps $2-4$ were repeated for 35 cycles. Final extension/elongation step $72^{\circ} \mathrm{C}$ for 40 seconds. Cooling of reaction process at step $4^{\circ} \mathrm{C}$ for 48 hours. was adopted.

The protocol employed by Maniatis, et al., (1982) [18] for preparation of Agarose gel electrophoresis

Amplification with amelogenin primers was at 330 base pair (bp) bands for X chromosome, and 218 base pair (bp) bands for Y chromosome, respectively.

With alphoid repeats primers, X-specific primer amplified at 130 base pair (bp) bands and Y-specific primer amplified at 170 base pair (bp) bands respectively.

The expected amplification products of amelogenin gene and alphoid repeats sequences were visualised by electrophoresis in $1.5 \%$ agarose gel containing $4 \mu \mathrm{l}$ ethidium bromide.

For amelogenin gene, a molecular weight marker was included in the middle and last lanes (Figures: 1a and $1 b)$, respectively.

For alphoid repeats, a molecular weight marker was included in the first lanes (Figures: $2 a$ and $2 b$ ).

Fisher's exact test (probability) and Z-test were employed for comparison of values. The sensitivity, specificity, efficiency, predictive value of positive tests, predictive value of negative tests, false positive rates and false negative rates of the PCR were determined according to the arithmetic definitions of these terms.

\section{Results}

Table 1 shows the result of PCR sex identification of the samples used in this study, with amelogenin gene. Amplification and genetic sex identification were achieved in four samples only (samples 4, 8, 11 and 12). Of these, only sample 8 amplified with both $X$ and $Y$ chromosomes. The others (samples 4, 11 and 12) amplified with only $\mathrm{Y}$ chromosome, thus, the $\mathrm{X}$ chromosome was negative. Amplification of $\mathrm{Y}$ chromosome for sample 11 was a band in a smear (smash band). Samples 1-3, 7, 9 and 10, produced smear only. Samples 5 and 6 were negative for both $\mathrm{X}$ and $\mathrm{Y}$ chromosomes. Sex identification was not achieved in samples that produced smear only (samples 1-3, 7, 9 and 10) and those that were negative (5 and 6).

Table 1: Results of Genetic Sex Identification of Unembalmed Bone (UEB) Samples Using Amelogenin Gene Primers.

\begin{tabular}{|c|c|c|c|c|c|}
\hline \multirow{2}{*}{$\begin{array}{l}\text { Bone fragment } \\
\text { serial number }\end{array}$} & \multirow[t]{2}{*}{ Bone sampled } & \multirow[t]{2}{*}{ Morphological sex } & \multicolumn{2}{|c|}{ PCR results with amelogenin gene primers } & \multirow[t]{2}{*}{ Genetic sex } \\
\hline & & & $\begin{array}{l}\text { X chromosome } \\
\text { amplification } \\
\text { (330 bp) }\end{array}$ & $\begin{array}{l}\text { Y chromosome } \\
\text { amplification } \\
(218 \mathrm{bp})\end{array}$ & \\
\hline UEB 1 & Little finger & Male & Smear & Smear & Unidentified \\
\hline UEB 2 & Capitate & Male & Smear & Smear & Unidentified \\
\hline UEB 3 & Lunate & Male & Smear & Smear & Unidentified \\
\hline UEB 4 & Hamate & Male & Negative & Positive & Male \\
\hline UEB 5 & Trapezium & Male & Negative & Negative & Unidentified \\
\hline UEB 6 & Scaphoid & Male & Negative & Negative & Unidentified \\
\hline UEB 7 & Middle finger & Male & Smear & Smear & Unidentified \\
\hline UEB 8 & Small toe & Male & Positive & Positive & Male \\
\hline UEB 9 & Triquatrum & Male & Smear & Smear & Unidentified \\
\hline UEB 10 & Pisiform & Male & Smear & Smear & Unidentified \\
\hline UEB 11 & Trapezoid & Male & Negative & Smash band at $218 \mathrm{bp}$ & Male \\
\hline UEB 12 & Index finger & Male & Negative & Positive & Male \\
\hline
\end{tabular}

Genetic sex identification was achieved in four samples $(4,8,11$ and 12) only (see Figures 1a and 1b). PCR Sensitivity $=40 \%$, Specificity $=100 \%$, Predictive value of positive test $=100 \%$, Predictive value of negative test $=25 \%$, False positive rate $=0 \%$, False negative rate $=150 \%$, Efficiency of test $=50 \%$. Fisher's exact probability test $\mathbf{P}=\mathbf{1}$. Z-test: $z$-value $=-1.0955, \boldsymbol{p}>\mathbf{0 . 0 5}$; not statistically significant. 


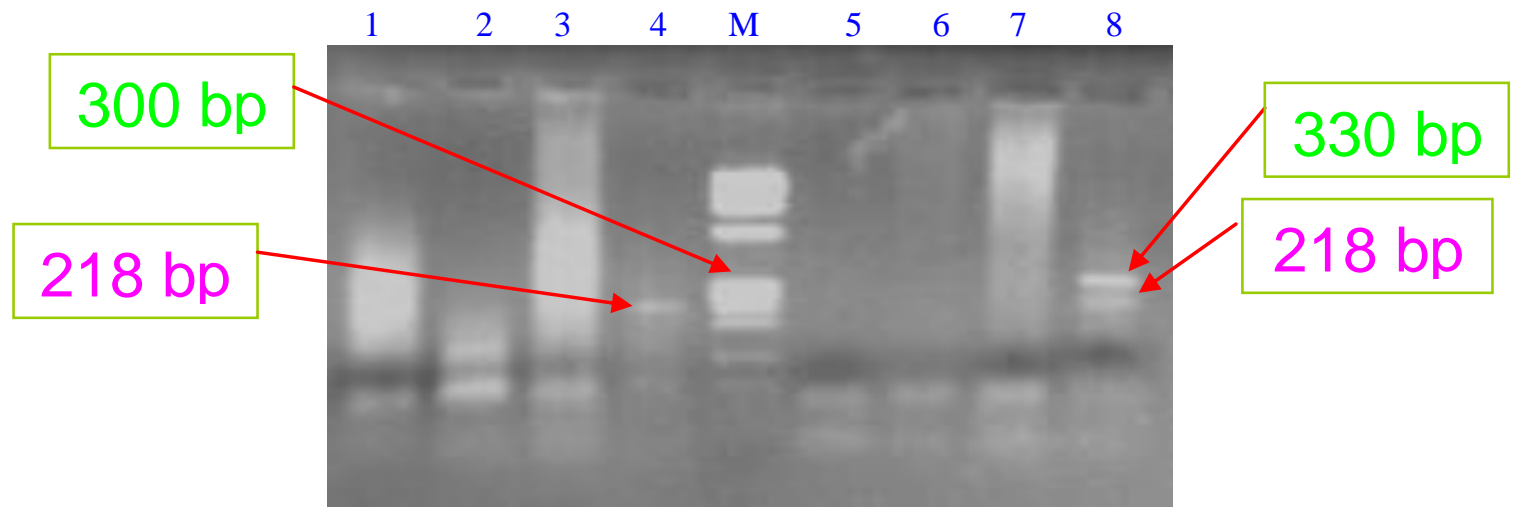

Figure 1a: Amplification of the amelogenin gene $\mathrm{X}$ and $\mathrm{Y}$ primers from the DNA of the unembalmed human bone fragments 1-8, electrophoretically separated on 1.5\% agarose gel (Reassay: 005/14).

Lanes: 1 = Little finger; $2=$ Capitate; $3=$ Lunate; $4=$ Hamate; $M=1000$ bp DNA ladder (Lot: 73020G3. Toyobo); 5 = Trapezium; $6=$ Scaphoid; $7=$ Middle finger; $8=$ Small toe.

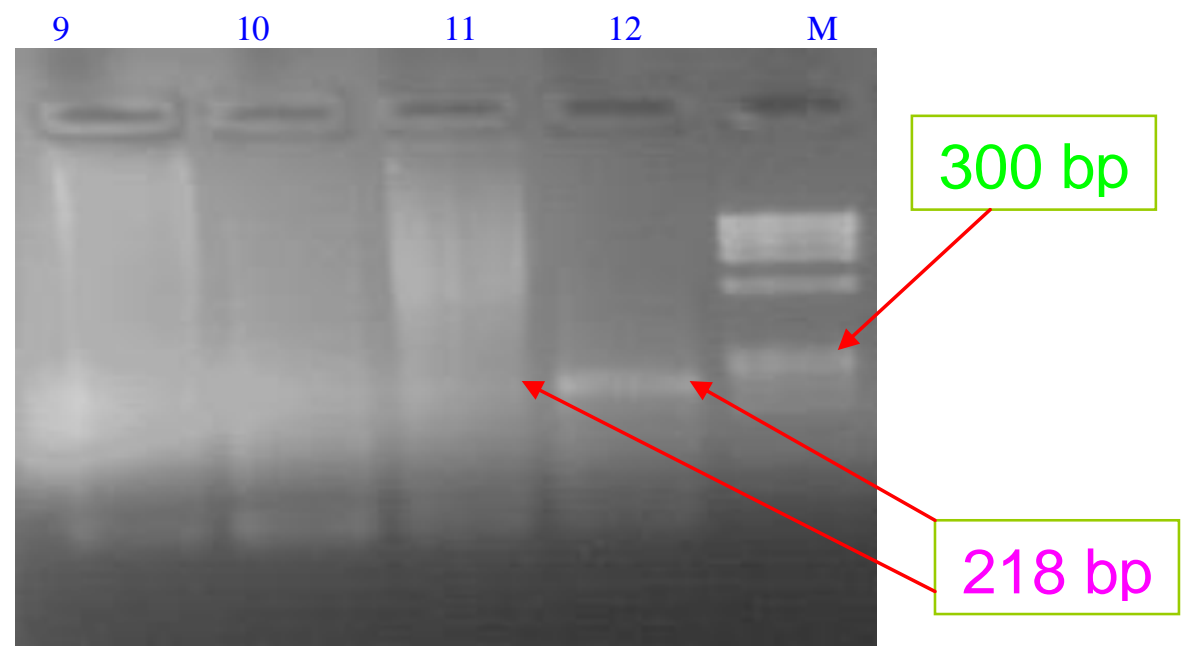

Figure 1b: Amplification of the amelogenin gene $\mathrm{X}$ and $\mathrm{Y}$ primers from the DNA of the unembalmed human fragments 9-12, electrophoretically separated on $1.5 \%$ agarose gel (Reassay: 005/14).

Lanes: $9=$ Triquatrum; $10=$ Pisiform; $11=$ Trapezoid; $12=$ Index finger; $\mathbf{M}=1000$ bp DNA ladder (Lot: 73020G3. Toyobo).

Details of the genetic sex identification for the samples using alphoid repeats primers are shown in Table 2. Amplifications for both $\mathrm{X}$ and $\mathrm{Y}$ chromosomes were achieved in all the samples. Correct genetic sex identification was achieved in all the samples. Thus, all the samples were genetically identified as males which agreed with their morphological sexes (males).

Table 2: Results of Genetic Sex Identification of Unembalmed Bone (UEB) Samples Using Alphoid

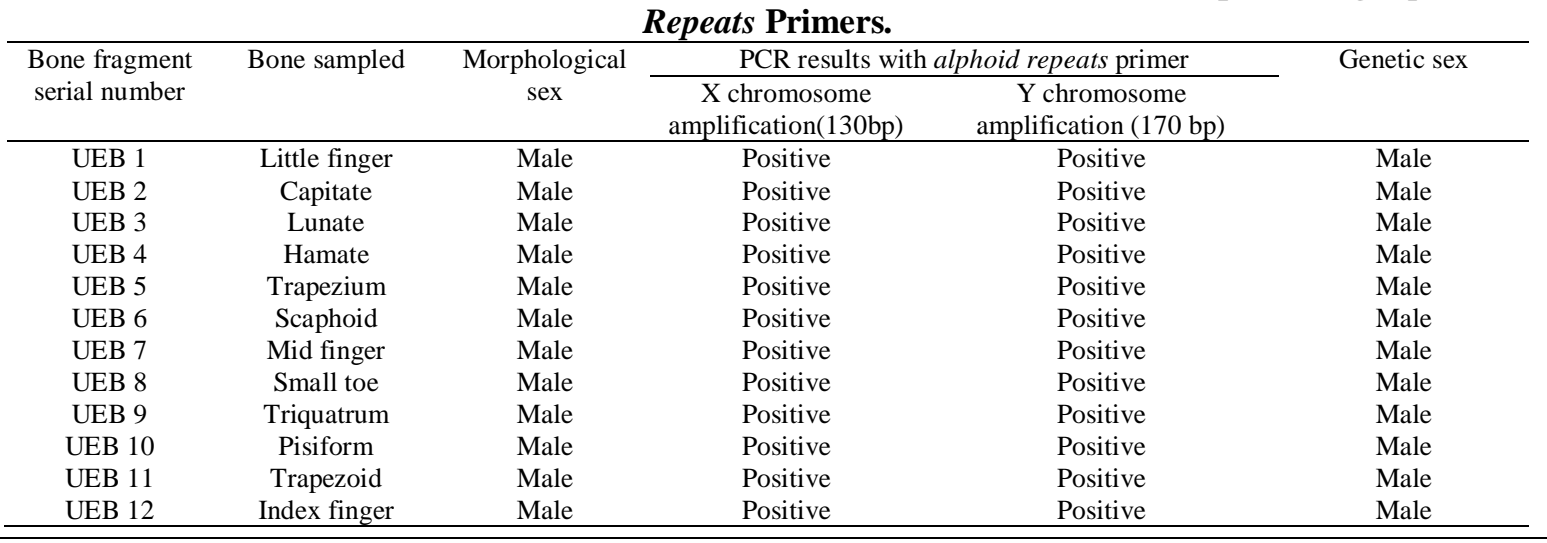


Correct genetic sex identification was achieved in all the samples. All the samples were males morphologically, and were genetically identified as males (see Table 2; Figures $2 \mathrm{a}$ and $2 \mathrm{~b}$ ). PCR Sensitivity = $100 \%$, Specificity $=0 \%$, Predictive value of positive test $=100 \%$, Predictive value of negative test $=0 \%$, False positive rate $=0 \%$, False negative rate $=0 \%$, Efficiency of test $=100 \%$. Fisher's exact probability test $\mathbf{P}=\mathbf{1}$. Ztest: $z$ - and $\boldsymbol{p}$ values were invalid.

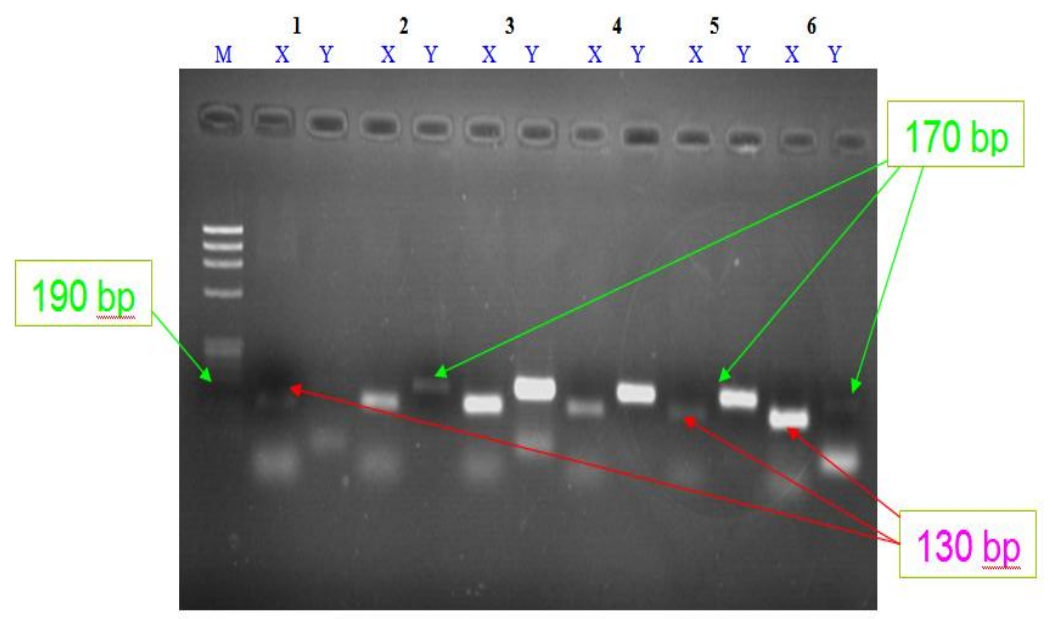

Figure 2a: Amplification of the alphoid repeats $\mathrm{X}$ and $\mathrm{Y}$ primers from the DNA of the unembalmed human bone fragments 1-6, electrophoretically separated on $1.5 \%$ agarose gel (Reassay: 005/14).

Lanes: $\mathrm{M}=1000$ bp DNA ladder (Lot: 73020G3. Toyobo); 1 = Little finger; 2 = Capitate; 3 = Lunate; 4= Hamate; $5=$ Trapezium; $6=$ Scaphoid.

Figure 2b: Amplification of the alphoid repeats $\mathrm{X}$ and $\mathrm{Y}$ primers from the DNA of the unembalmed human bone fragment 7-12, electrophoretically separated on 1.5\% agarose gel (Reassay: 005/14).

Lanes: $\mathrm{M}=1000$ bp DNA ladder (Lot: 73020G3. Toyobo); $7=$ Middle finger; $8=$ Small toe; $9=$ Triquatrum; $10=$ Pisiform; $11=$ Trapezoid; $12=$ Index finger.

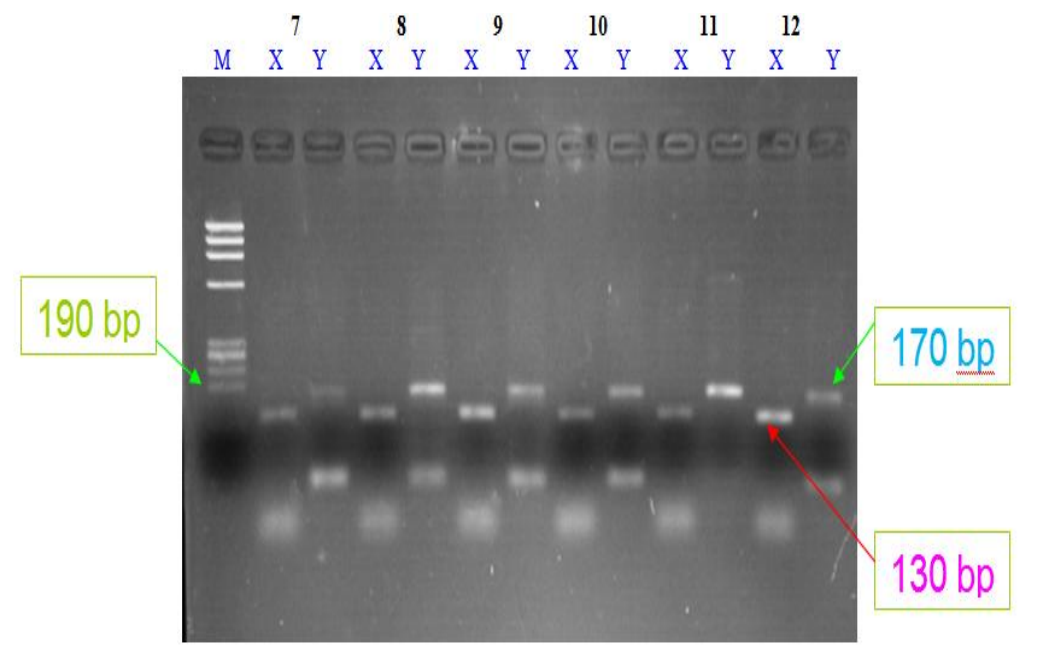

Figure 2b: Amplification of the alphoid repeats $\mathrm{X}$ and $\mathrm{Y}$ primers from the DNA of the unembalmed human bone fragment 7-12, electrophoretically separated on $1.5 \%$ agarose gel (Reassay: 005/14).

Lanes: $\mathrm{M}=1000$ bp DNA ladder (Lot: 73020G3. Toyobo); $7=$ Middle finger; $8=$ Small toe; $9=$ Triquatrum; $10=$ Pisiform; $11=$ Trapezoid; $12=$ Index finger.

Table 3 compares the results of genetic sex identification of the samples between amelogenin gene and alphoid repeats primers. Amplification of both chromosomes with amelogenin gene was achieved in sample 8 only. Amplification of Y chromosome only, with amelogenin gene, was achieved in samples 4, 11 (with smash band at the right size) and 12. With amelogenin gene, both $\mathrm{X}$ and $\mathrm{Y}$ chromosomes showed either smear only (samples 1-3, 7, 9 and 10) or no amplification at all (X chromosome of samples 4 and 11 and both $\mathrm{X}$ and $\mathrm{Y}$ 
chromosomes of samples 5 and 6). Consequently, the genetic sexes of only samples 4, 8, 11 and 12 were correctly identified. Thus, genetic sex identification was not achieved with amelogenin gene, for the remaining samples. With alphoid repeats, amplification of both $\mathrm{X}$ and $\mathrm{Y}$ chromosomes was achieved in all the samples. Therefore, correct genetic sex identification for all the samples was achieved with alphoid repeats.

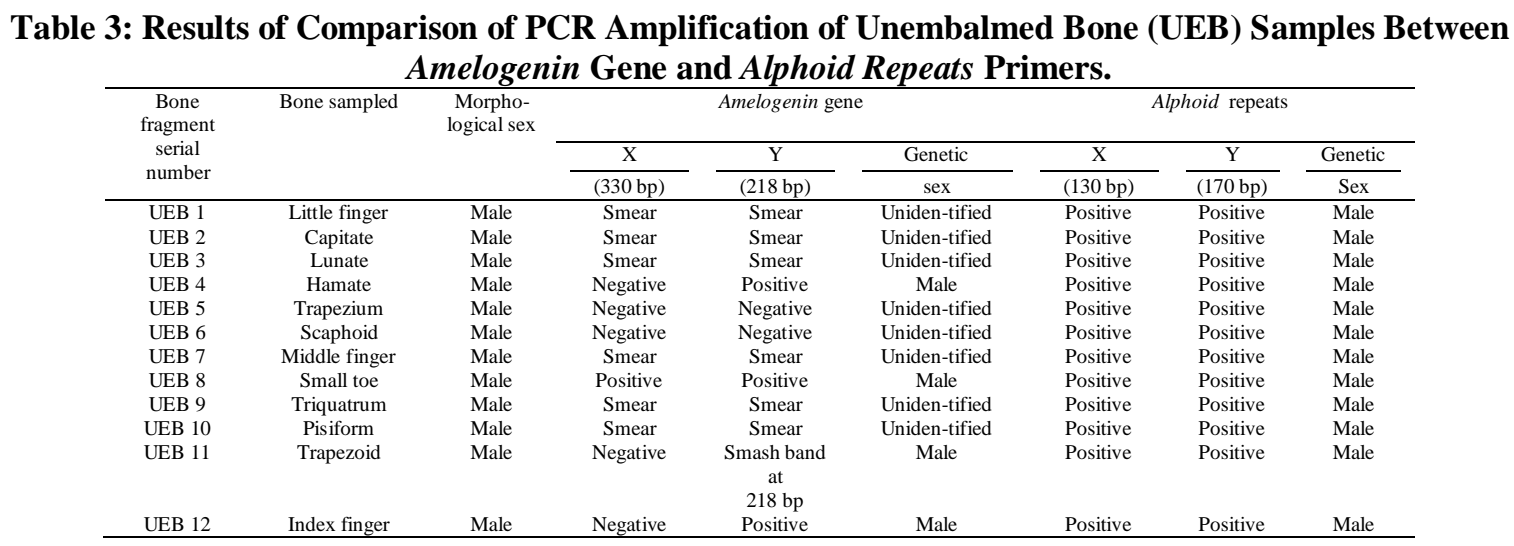

With amelogenin gene, the genetic sexes of only samples 4, 8, 11 and 12 were identified. Genetic sex identification for all the samples was achieved with alphoid repeats.

\section{Discussion}

Qualitative work on medical genetics is problematic and scientific progress in this very important and topical field is very slow in Nigeria. This slow progress is attributable to paucity of the necessary, basic investigatory facilities [19]. DNA-based sex determination of skeletal remains was first performed by amplification of Y chromosome-specific sequences [20], a method that this study employed. In this study, primers that span short DNA fragments from the amelogenin-encoding gene and alphoid repeats were used for sex determination from unembalmed human skeletal fragments.

With the use of amelogenin gene in the twelve (12) unembalmed human skeletal fragments used in this study (Table 1; Figures 1a and 1b), amplification and genetic sex identification were achieved in four samples (samples 4, 8, 11 and 12) only. Of these, only sample 8 amplified with both $\mathrm{X}$ and $\mathrm{Y}$ chromosomes. The others (samples 4, 11 and 12) amplified with only $\mathrm{Y}$ chromosome, thus, the $\mathrm{X}$ chromosome was negative.

Amplification of $\mathrm{Y}$ chromosome in sample 11 was a band in a smear (smash band) at $218 \mathrm{bp}$ (right size). Samples 1-3, 7, 9 and 10, produced smear only. Samples 5 and 6 were completely negative (no band, no smear) for both $\mathrm{X}$ and $\mathrm{Y}$ chromosomes. Genetic sex identification was not achieved in samples that produced only smear (samples 1-3, 7, 9 and 10), and in those that were completely negative (no band, no smear) for both $\mathrm{X}$ and $\mathrm{Y}$ chromosomes (samples 5 and 6). The genetic sexes of the samples that were identified as males (samples 4, 8, 11 and 12), agreed with their respective morphological sexes (males).

Presence of smear is an indication of presence of DNA in a sample. However, such DNA could not produce a definite and specific band to allow accurate genetic sex identification. This usually results from inefficient priming or inefficient extension [21]. A series of PCRs containing different concentrations of the primers was set to find the optimal concentration. A series of touchdown PCRs containing different concentrations of $\mathrm{Mg}^{2+}$ to find the optimal concentration was also employed to improve the amplification. Again, a minimum possible temperature for annealing step was used. Finally, adjuvants such as bovine serum albumin (BSA) and dimethyl sulfoxide (DMSO) were separately added to the reaction mixture, as suggested by Sambrook and Russell, 2001 [21]. However, all these remedies did not yield better result than the ones presented or shown here.

Negative amplification of either X or Y chromosome is indicated by empty gel wells, without smear or visible band on the gel (samples 5 and 6). Failure of amplification could result from errors in PCR buffer formulation, failure to load sample DNA and errors in loading sample into gel wells. The remedy lies in demonstrating the presence of DNA in the sample using for example the X-specific primers, and repeatedly amplifying the putative female sample with the Y-specific primers and obtaining negative results (no band

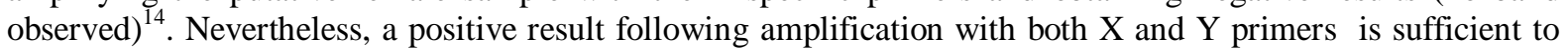
identify the sample as male [22]. Negative amplification could mean that the DNA was not retrievable, i.e. there was no amplifiable DNA for the primers employed by this study, in such samples. Thus, the DNA could have been severely degraded by multiple factors, to single strands or the base sequences were too short for the 
primers employed to amplify this DNA. As well, failure to amplify a DNA may result from the presence of PCR inhibitors which interfere with the PCR reaction $[23,24]$.

Sample eleven (11) that amplified with only Y chromosome with a smash band at 218 base pairs (bp), as shown in Figure 1b, could not be dependable in conclusive decision making on the gender identification of the sample.

A preferential amplification of $\mathrm{Y}$ chromosome was noticed in the samples. This was similarly reported by Faerman et al., 1995 [14] and Matheson and Loy, 2001 [15]. The higher sensitivity of detection of the Y chromosome might be due to the shorter amplification product or to the nature of the allele-specific primers. Regardless of the reason, this suggests that this method (sex identification with amelogenin gene) is more prone to miss a female specimen than a male. On the other hand, the more efficient amplification of the $\mathrm{Y}$ allele suggests that presence of a single 330 bp product indicates a female [14].

The success rate for gender identification with amelogenin gene in this study was $33.3 \%$ only. However, this is favourably comparable with reports by earlier workers who conducted similar studies on bone fragments using amelogenin gene. In 1995, Faerman et al., 1995 [14], reported 41\% success rate, Faerman et al., 1998[25] reported 44\% success, Mays and Faerman, 2001[26] reported 42\% and Matheson and Loy, 2001 [15] reported $40 \%$. Amelogenin PCR applied to larger number of Etruscan samples shows a low success rate (Vernessi et al., 1999 [27].

PCR sex identification for the samples using alphoid repeats primers recorded $100 \%$ success rate. Amplification was achieved for both $\mathrm{X}$ and $\mathrm{Y}$ chromosomes in all the samples (Table 2, Figures 2a and 2b). There was correct genetic sex identification for all the samples. Thus, there was no discrepancy between the genetic and morphological male sexes of the samples. The bands produced were sharp and of the right molecular weight; $130 \mathrm{bp}$ for $\mathrm{X}$ and $170 \mathrm{bp}$ for $\mathrm{Y}$ chromosomes, respectively.

Comparing the results of genetic sex identification of the samples between amelogenin gene and alphoid repeats primers (Table 3), this study has found that with amelogenin gene, although 4 samples amplified (samples 4, 8, 11 and 12), amplification of both $\mathrm{X}$ and $\mathrm{Y}$ chromosomes was achieved in only one sample (sample 8). The others (samples 4, 11 and 12), amplified with Y chromosome only, thus, the $\mathrm{X}$ chromosome did not amplify. The remaining samples in this group showed either smear only (samples 1-3, 7, 9 and 10), or no amplification (negative) at all (samples 5 and 6). Hence, the success rate for genetic identification was $33.3 \%$ only. However, with alphoid repeats, amplification of both $\mathrm{X}$ and $\mathrm{Y}$ chromosomes was achieved in all the samples. There was $100 \%$ success rate of genetic sex identification for the samples, with alphoid repeats. The genetic sexes of these samples confirmed their morphological sexes (males), and this was based on the amplification of both $\mathrm{X}$ and $\mathrm{Y}$ chromosomes of the samples, with alphoid repeats. Although, with amelogenin gene, only four samples $(4,8,11$ and 12), amplified, their genetic sexes were correctly identified as males, and agreed with the identification (males) by the alphoid repeats primers, as indicated above. However, the genetic sex identification of these four samples was based on the amplification of only the $Y$ chromosome in samples 4 , 11 (with smash band at 218) and 12, and amplification of both X and $\mathrm{Y}$ chromosomes in sample 8, as found with alphoid repeats in all the samples. Failure of amplification and subsequent inability to genetically identify the sexes of samples 1-3, 5-7, 9 and 10, with amelogenin gene, but having achieved it (amplification and correct genetic sex identification) with alphoid repeats, could be due to the fact that the base sequence of amelogenin gene primers are larger (330 bp and $218 \mathrm{bp}$, respectively, for $\mathrm{X}$ and $\mathrm{Y}$ chromosomes) than their counter parts (130 bp and $170 \mathrm{bp}$, respectively, for $\mathrm{X}$ and $\mathrm{Y}$ chromosomes) in alphoid repeats.

\section{Conclusions}

The study, has demonstrated the applicability of PCR method of sex determination in unembalmed human skeletal fragments from Sokoto, Northwestern Nigeria. With amelogenin gene primers, correct genetic sex identification was achieved in four samples only. With alphoid repeats primers, correct genetic sex identification was achieved in all the samples. Therefore, alphoid repeats is more efficient and more reliable than amelogenin gene, in sex determination from unembalmed human skeletal fragments. This is the first known study determining the sex of unembalmed human skeletal fragments by means of PCR in Nigeria. There is need for further studies in Nigeria to complement the findings of this study.

\section{Acknowledgements}

We wish to thank the Education Trust Fund, Usmanu Danfodiyo University, Sokoto, Nigeria for the grant to undertake the bench work of this study at the Department of Medical Molecular Genetics, Division of Human Genetics and Genome Research, National Research Centre, Cairo, Egypt. 


\section{References}

[1]. E. S. M. Iwamura, J. A. Soares-Vieira, D. R. Munoz, Human identification and analysis of DNA in bones. Rev Hosp Clin Fac Med Sao Paulo, 59 (2004) 383-8.

[[2]. S. Andelinovic, D. Sutlovic, I. E. Ivkosic, V. Skaro, A. Ivkosic, F. Paic, et al., Twelve-year experience in identification of skeletal remains from mass graves. Croat Med, 46 (2005) 530-9.

[3]. F. S. Rhonan, D. R. P. Savio, D. J. Eduardo, S. S. B. Rejane, M. O. G. Neide, S. Rafael, Genetics and molecular biology: a literature review of forensic dentistry application. BrazilianJournal of Oral Sciences, 6(20) (2007) 1254-1259.

[4]. R. Lleonart, E. Riego, R. R. Suarez, R. T. Ruiz, J. Fuente Analyses of DNA from ancient bones of a pre-Columbian Cuban woman and a child. Genet Mol Biol, 22 (1999) 285- 9.

[5]. C.Vernesi, G. Benedetto, D. Caramelli, E. Secchieri, L. Simoni, E. Katti, et al., Genetic characterization of the body attributed to the evangelist Luke. Proc Natl Acad Sci. 98 (2001) 13460-3.

[6]. M. Ogata, R Mattern, P. M. Schneider, U. Schacker, T. Kaufmann, C. Rittner, Quantitative and qualitative analysis of DNA extracted from post-mortem muscle tissues. Z Rechtsmed, 103 (1990) 397-406.

[7]. N. Wurmb-Schwark, M. Harbeck, U. Wiesbrock, I. Schroeder, S. Ritz-Timme, M. Oehmechen, Extraction and amplification of nuclear and mitochondrial DNA from ancient and artificially aged bones. Leg Med, 5 (2003) 169-72.

[8]. K. Bender, M. J. Farfan, P. M. Schneider, Preparation of degraded human DNA under controlled conditions. Forensic Sci Int, 139 (2004) $135-40$.

[9]. U. Pillay, B. Kramer. A simple method for the determination of sex from the pulp of freshly extracted human teeth utilizing the polymerase chain reaction Journal of the Dental Association of the South Africa, 52 (1997) 673-677.

[10]. A. Akane, H. Shiono, K. Matsubara, H. Nakamura, M. Hasegawa, M. Kagawa, Purification of forensic specimens for the polymerase chain reaction (PCR) analysis. Journal of Forensic Sciences, 38 (1993) 691-701.

[11]. W. Harvey Dental Identification and Forensic Odontology. London: Henry Kimpton Publishers, 1976 Ch. 6, pp 36-37; Ch. 11, pp 67-68.

[12]. A. Cooper, H. N. Poinar, Ancient DNA: Do it right or not at all. Science, 289 (2000) 1139.

[13]. Department of Medical Molecular Genetics, Division of Human Genetics and Genome Research, National Research Centre, Cairo, Egypt, (2010).

[14]. M. Faerman, D. Filon, G. Kahila, C. L. Greenblatt, P. Smith, A. Oppenheim, Sex identification of archaeological human remains based on amplification of the X and Y amelogenin alleles. Gene, 167 (1995) 327-332.

[15]. D. E. Matheson, T. H. Loy, Genetic Sex Identification of 9400-old Human skull Samples from Cayönü Tepesi, Turkey. Journal of Archaeological Science, 28 (2001) 569-575.

[16]. M. Witt, R. P. Erickson, A rapid method for detection of Y-chromosomal DNA from dried blood specimens by the polymerase chain reaction. Hum Genet, 82 (1989) 271-274.

[17]. H. Murakami, Y. Yamamoto, K. Yoshitome, T. Ono, O. Okamoto, Y. Shigeta, et al., Forensic study of sex determination using PCR on teeth samples. Acta Med Okayama, 54 (2000) 21-32.

[18]. T. Maniatis, E. F. Fritchs, J. Sambrook. Molecular cloning: A Laboratory Manual. New York: Cold Spring Harbor Laboratory, (1982) pp 468.

[19]. H.Ahmed, The Status of Paediatrics Practice and Research in Nigeria with Reference to Genetics: A Plea for Establishment of Medical Genetics Research Centre. Annals of African Medicine, 2 (2) (2003) 88-98.

[20]. S. Hummel, B. Herrman, Y-chromosome-specific DNA amplified in Ancient human. Naturwissenschaften, 78 (1991) $266-267$.

[21]. J. Sambrook, D. W. Russell. Molecular Cloning: A Laboratory Manual, $3^{\text {rd }}$ ed., Cold Spring Harbor Laboratory Press, (2001) ISBN 0-8769-576-5.

[22]. S. Paabo, J. A. Gifford, A. C. Wilson, Mitochondrial DNA sequences from a 7000-year old brain. Nucleic Acids Res, 16 (1988) 9775-87.

[23]. E. Hagelberg, L. S. Bell, T. Allen, A. Boyde, S. J. Jones, J. B. Clegg, Analysis of ancient DNA: techniques and applications. Philos. Trans. R. Soc. Lond. Biol, 333 (1991) 399-407.

[24]. M. Q. Sutton, M. Malik, A. Ogram Experiments on the determination of gender from Coprolites by DNA analysis. Journal of Archaeological Science, 23 (1996) 263-267.

[25]. M. Faerman, K. G. Bar-Gal, D. Filon, C.L. Greenblatt, L. Stager, A. Oppenheim, et al, Determining the Sex of Infanticide Victims from the Late Roman Era through Ancient DNA Analysis. Journal of Archaelogical Science, 25 (1998) 861-865.

[26]. S. Mays, M. Faerman, Sex Identification in Some Putative Infanticide Victims from Roman Britain Using Ancient DNA. Journal of Archaeological Science, 28 (2001) 555-559.

[27]. C. Vernesi, D. Caramelli, S. Carbonelli Sala, B. Chiarelli, Molecular sex determination of Etruscan bone samples (7th-3 ${ }^{\text {rd }}$ c. BC): a reliability study. Homo, (1999) 118-126. 